\title{
Neonatal diabetes mellitus due to a new KCNJ11 mutation - 10 years of the patient's follow-up
}

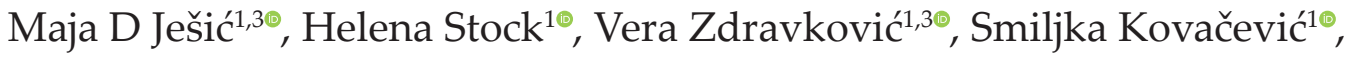 \\ Marko Savićc ${ }^{\circ}$, Miloš M Ješić ${ }^{2,3 \odot}$ \\ ${ }^{1}$ Department of Pediatric Endocrinology, ${ }^{2}$ Department of Neonatology, University Children's Hospital Tiršova, Belgrade, ${ }^{3}$ Faculty of \\ Medicine, University of Belgrade, Serbia and ${ }^{4}$ Institute of Medical Statistics and Informatics, Faculty of Medicine, Belgrade, Serbia.
}

\begin{abstract}
Background. Mutations in the KCNJ11 gene, which encodes the Kir6.2 subunit of the ATP-sensitive potassium channel, often result in neonatal diabetes.

Case. In this report, we describe a 10-year-old girl who is heterozygous for a new missense mutation in the KCNJ11 gene and whose treatment was successfully switched from insulin to sulfonylurea (glibenclamide) therapy when she was one month old. 10-year data on a low-dose of glibenclamide monotherapy showed excellent glycaemic control with no reports of severe hypoglycaemia and microvascular complications.
\end{abstract}

Conclusion. An early genetic diagnosis of neonatal diabetes mellitus is highly beneficial because early switch from insulin to sulfonylurea is safe, avoids unnecessary insulin therapy and promotes sustained improvement of glycaemic control on long-term follow-up.

Key words: neonatal diabetes mellitus, new KCNJ11 mutation, sulfonylurea therapy.

Neonatal diabetes mellitus (NDM) is defined as the occurrence of diabetes mellitus within the first 6 months of life. It is a rare disease ( 1 in 400,000 live births) caused by genetic mutations that can occur spontaneously or be inherited from parents. ${ }^{1,2}$ Affected infants frequently present with symptomatic hyperglycaemia and sometimes ketoacidosis. ${ }^{2}$ The most common causes of permanent NDM are mutations in the KCNJ11 and $A B C C 8$ genes which encode the two protein subunits (Kir6.2 and sulfonylurea receptor 1, SUR1, respectively) of the ATP-sensitive potassium $\left(\mathrm{K}_{\mathrm{ATP}}\right)$ channel on pancreatic $\beta$-cells. The identification of the underlying genetic cause has led to improved treatment for patients with mutations in the KCNJ11 and ABCC8 genes. ${ }^{2}$ Successful switch from insulin to oral sulfonylurea (SU) therapy with excellent initial glycaemic control has

$凶$ Miloš D Ješić

milos.jesic@udk.bg.ac.rs

Received 26th May 2020, revised 7th September 2020,

24th October 2020, accepted 26th November 2020. been reported in the majority of patients with KCNJ11 mutations. ${ }^{3-5}$ A key question is whether the excellent results in neonatal diabetes will be maintained or whether long-term therapy will cause SU failure or adverse effects. We report the 10-year effect of the switch from insulin to SU (glibenclamide) in a patient carrying the new missense mutation, V252L, in the KCNJ11 gene.

\section{Case Report}

A 10-year-old girl presented with marked hyperglycaemia ranging from 10 to $20 \mathrm{mmol} / \mathrm{L}$ and glucosuria without ketones on the fourth day of life. This patient had low birth weight (the birth weight of this full-term female neonate was $2780 \mathrm{~g}$, on the $5.32^{\text {th }}$ percentile, -1.62 SDS). The patient was born to a 31-year-old mother whose pregnancy was uneventful. The physical examination was normal. There were no other factors (sepsis, infection, dextrose-containing intravenous fluids) that could account for the hyperglycaemia. In addition, there was no family 
history of diabetes mellitus or hyperglycaemic disorders. On the fifth day of life, blood glucose was $18 \mathrm{mmol} / \mathrm{L}$ and urine contained 1+ glucose without ketones. The patient's C-peptide concentration was $0.18 \mathrm{nmol} / \mathrm{L}$ (normal 0.2982.35) and the serum insulin level was $2.8 \mu \mathrm{IU} /$ $\mathrm{ml}$ (normal 7-24), with a concomitant plasma glucose level of $21 \mathrm{mmol} / \mathrm{L}$.

The initial management of the patient's hyperglycaemia included insulin therapy. At first the patient received infusions of regular insulin at a dose of $0.1-0.2$ units $/ \mathrm{kg} / \mathrm{h}$. On day 8 the infusions were discontinued, and the treatment was switched to a subcutaneous insulin regimen with short-acting human insulin (used to correct hyperglycaemia) and intermediate-acting insulin (administered three times a day to provide basal insulin needs). All in all, she received a daily dose of approximately 2 units $/ \mathrm{kg} /$ day of insulin. During the neonatal period, genetic analysis was carried out at the Peninsula Medical School, Universities of Exeter \& Plymouth. Subsequent testing for mutations associated with PNDM showed that the patient was heterozygous for a new missense mutation, V252L, in the KCNJ11 gene. ${ }^{6}$ The patient's mother was negative for the same mutation and the father was not the patient's biological father.

The patient was one month old when the transition from insulin to oral glibenclamide started at an initial dose of $0.12 \mathrm{mg} / \mathrm{kg} /$ day, twice daily. This initial dose was increased over the next 7 days to $0.2 \mathrm{mg} / \mathrm{kg} /$ day, while regular insulin was simultaneously tapered off. Her hyperglycaemia resolved completely once her glibenclamide dose was increased to $0.3 \mathrm{mg} / \mathrm{kg} /$ day, twice daily, and doses of regular insulin were no longer required. Over the following two weeks the need for glibenclamide slowly decreased and stabilized at $0.2 \mathrm{mg} / \mathrm{kg} /$ day and her blood sugar levels reached an average of around $10 \mathrm{mmol} / \mathrm{L}$.

Five months after starting glibenclamide, the patient remained asymptomatic ( $\mathrm{HbA} 1 \mathrm{c} 5.8 \%)$; she was gaining weight and showing normal neurodevelopmental progress at follow-up.
Her serum C-peptide level was $1.4 \mathrm{nmol} / \mathrm{L}$, showing an eight-fold increase over that seen during insulin treatment alone when C-peptide was $0.18 \mathrm{nmol} / \mathrm{L}$. Oral glucose tolerance test (glucose, $1.75 \mathrm{~g} / \mathrm{kg}$ ) was done one year after the sulfonylurea transition. The results showed the improvement of C-peptide secretory response during treatment. Glucose (0 min-120 min) and C-peptide (0 min-120 min) increased from basal glucose $5.5 \mathrm{mmol} / \mathrm{L}$ to $9 \mathrm{mmol} / \mathrm{L}$ and from basal C-peptide $0.4 \mathrm{nmol} / \mathrm{L}$ to $2.1 \mathrm{nmol} / \mathrm{L}$. Subsequent clinical follow-up visits were at 6 to 12 month intervals. During the follow-up, height and weight were measured, self-monitored blood glucose levels were recorded, HbA1c was measured, and renal and liver function tests were performed.

The patient is now 10 years of age; her height is $140 \mathrm{~cm}\left(80^{\text {th }}\right.$ percentile), she weighs $30.5 \mathrm{~kg}$ $\left(50^{\text {th }}\right.$ percentile) and shows signs of sexual development (Tanner stage 3). She has normal mental and social skills and strong motivation to learn at school. Recent glibenclamide dose was $0.3 \mathrm{mg} / \mathrm{kg}$ per day and her $\mathrm{HbA1c}$ was $6.1 \%$. The dosage of glibenclamide was adjusted in accordance with the patient's blood glucose profile and median glibenclamide dose was $0.16 \mathrm{mg} / \mathrm{kg} /$ day (0.07-0.3 mg/kg/day) during the ten year of the follow-up period. Under stressful conditions, e.g. while suffering from a mild childhood infection, blood glucose levels remained within the range of $6-10 \mathrm{mmol} / \mathrm{L}$ on glibenclamide therapy. Excellent glycaemic control was maintained over the follow-up years and the median of $\mathrm{HbA} 1 \mathrm{c}$ was $5.9 \%$ (5.6-6.4\%; see Fig.1). The median of fasting C-peptide values was $1.8 \mathrm{nmol} / \mathrm{L}(1.4-2.0 \mathrm{nmol} / \mathrm{L})$ based on 27 measurements over a 9-year period. No reports of severe hypoglycaemia and microvascular complications were recorded. No symptoms leading to suspicion of adverse effects caused by sulfonylurea, including the yellowing of the teeth, gastrointestinal adverse effects, renal and liver dysfunction have been noticed since the switch from insulin to sulfonylurea. A written consent was obtained from the parents for publication purposes. 


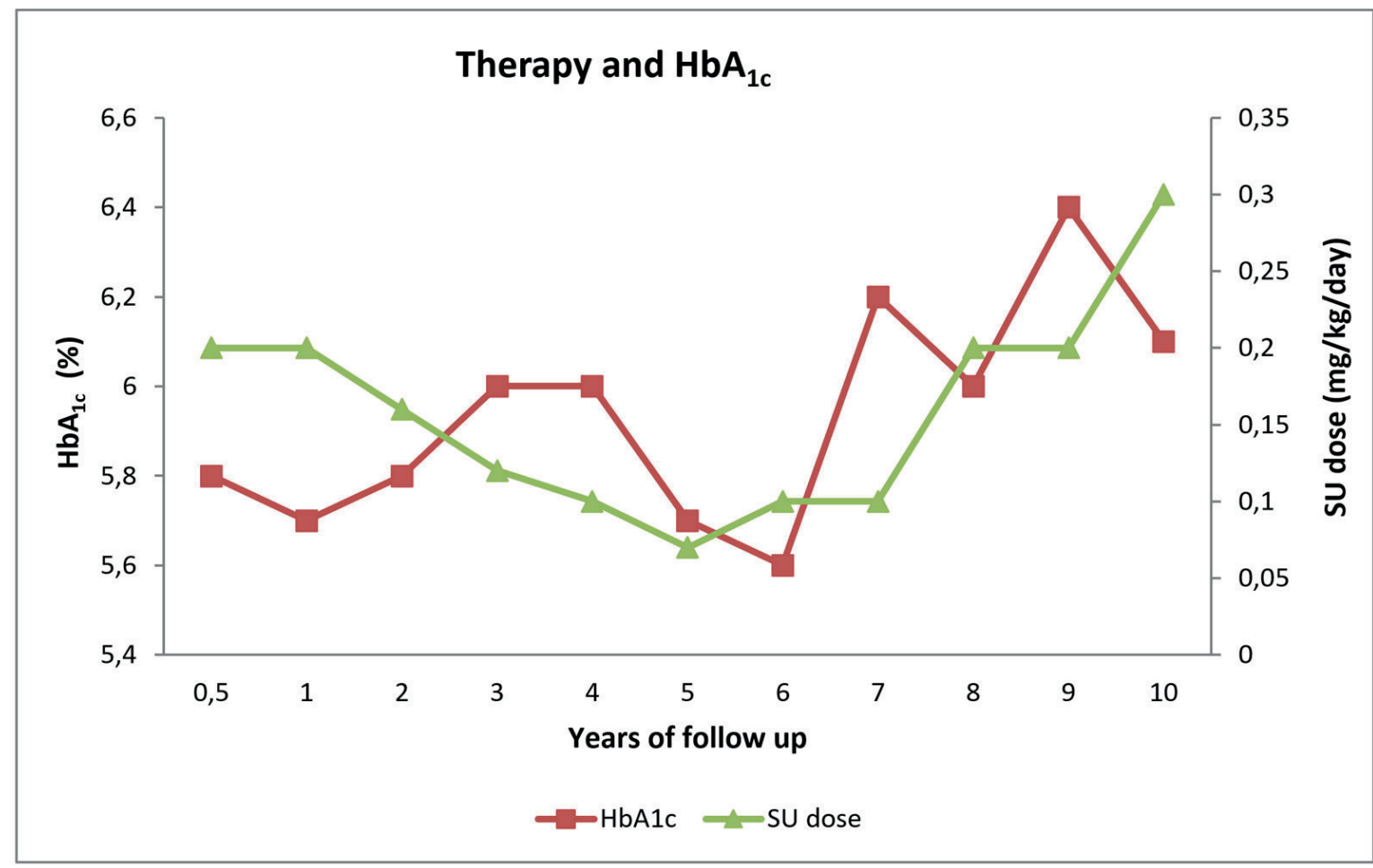

Fig. 1. Overview of the treatment and $\mathrm{HbA}_{1 \mathrm{c}}$ levels during the follow-up of patient with permanent NDM attributable to a V252L in the KCNJ11 gene. Treatment and $\mathrm{HbA}_{1 \mathrm{c}}$ levels: the point of initial switch from insulin to sulfonylurea is 0 years. Green line with triangles shows sulfonylurea (glibenclamide) dose (mg/kg/day) and red line with squares shows $\mathrm{HbA}_{1 \mathrm{c}}$ levels (\%). The dose of sulfonylurea glibenclamide was calculated as the sum of the sulfonylurea doses (in $\mathrm{mg}$ ) during a day divided by the weight in $\mathrm{kg}$.

\section{Discussion}

The number of genes that are found in children with neonatal diabetes continues to increase and there are more than 20 known genetic causes for NDM..$^{7-10}$ The various genes are associated with specific inheritance pattern, phenotype, and clinical features. ${ }^{7}$ In a large series of 1020 patients diagnosed with NDM before 6 months of age, mutations in the potassium channel genes, KCNJ11 and $A B C C 8$, were found in $38.2 \%$ of neonatal diabetes but were identified less frequently in consanguineous families. ${ }^{7}$ The clinical presentation varies from incidentally detected asymptomatic hyperglycaemia to severe dehydration and diabetic ketoacidosis (DKA). ${ }^{11}$ A genetic diagnosis is crucial, because at least $90 \%$ of patients can transfer from insulin injections to oral SU. ${ }^{12}$ After transferring to SU treatment, patients have improved glycaemic control at 1 year, without an increase in hypoglycaemia and with less glycaemic variability; however, the key question that remains unanswered is whether the excellent results in NDM will be maintained in the long term. ${ }^{12-14}$

Our patient is one of the youngest patients to commence oral SU therapy for the treatment of NDM because of a new KCNJ11 mutation, and in a 10-year follow-up SU therapy has been proven safe and effective. The patient maintained excellent glycaemic control without the usual adverse effects of hypoglycaemia. In addition, our result is consistent with the findings of the first study of long-term efficacy and safety of SU that showed that SU failure is not a feature of KCNJ11 permanent neonatal diabetes. ${ }^{15}$ For the 81 patients included in the study which did not include our patient, the median age at diabetes diagnosis was 8.0 weeks, the median age at transfer from insulin to SU was 4.8 years 
and $75(93 \%)$ of 81 participants remained on SU therapy alone for the 10-year duration. In these patients, the response dose of $S U(0.5 \mathrm{mg} / \mathrm{kg} /$ day vs $0.3 \mathrm{mg} / \mathrm{kg} /$ day in our patient) and the median maintenance dose of $S U(0.23 \mathrm{mg} / \mathrm{kg} /$ day vs 0.16 $\mathrm{mg} / \mathrm{kg} /$ day in our patient) was higher than in our patient whose treatment was successfully switched from insulin to glibenclamide therapy when she was only a month old. Earlier age at the initiation of SU treatment is associated with an improved response to SU therapy and could also lead to a lower maintenance dose which is in contrast with data from a large international cohort study. ${ }^{15}$

A few individuals who initially responded to sulfonylurea (6 of 81 patients) showed worsening glycaemic control on SU monotherapy. ${ }^{15}$ The median age at sulfonylurea initiation was 7.4 years and the median age at insulin initiation was 15 years. This fact is important because puberty is associated with increased insulin resistance and suboptimal treatment adherence in diabetes. Patients requiring reintroduction of insulin were on a fairly modest $\mathrm{SU}$ dose (median $0.27 \mathrm{mg} / \mathrm{kg} / \mathrm{day}$, range $0.19-0.43$ ), suggesting there was capacity to increase the dose further. ${ }^{15}$ Taken together, their data suggest that factors other than sulfonylureas having stopped working at the level of the $\mathrm{K}_{\text {ATP }}$ channel might have contributed to the need for the addition of insulin treatment in these patients. This finding contrasts with the SU monotherapy noted in our 10-year-old patient with signs of puberty (Tanner stage 3). The SU dose was increased at the beginning of puberty from 0.2 to $0.3 \mathrm{mg} / \mathrm{kg}$ per day in accordance with the patient's blood glucose profile with satisfactory glycaemic control.

In conclusion, we presented one of the youngest patients to commence oral glibenclamide therapy for the treatment of NDM because of a novel Kir6.2 mutation. An early genetic diagnosis of NDM is important because early switch from insulin to $\mathrm{SU}$ is safe, avoids unnecessary insulin therapy, and promotes sustained improvement of glycaemic control on long-term follow-up.

\section{Author contribution}

Clinical data and preparation of the manuscript: Maja D Ješić; laboratory analysis: Helena Stock; clinical data: Vera Zdravković, Smiljka Kovačević; statistical analysis: Marko Savić; clinical advisor: Miloš Ješić.

\section{Conflict of interest}

The authors declare no conflict of interest.

\section{REFERENCES}

1. Sperling MA. ATP-sensitive potassium channels - neonatal diabetes mellitus and beyond. N Engl J Med 2006; 355: 507-510.

2. Aydin BK, Bundak R, Bas F, et al. Permanent neonatal diabetes mellitus: same mutation, different glycaemic control with sulfonylurea therapy on long-term follow up. J Clin Res Pediatr Endocrinol 2012; 4: 107-110.

3. Klupa T, Skupien J, Mirkiewicz-Sieradzka B, et al. Efficacy and safety of sulfonylurea use in permanent neonatal diabetes due to KCNJ11 gene mutations: 34-month median follow-up. Diabetes Technol Ther 2010; 12: 387-391.

4. Vendramini MF, Gurgel LC, Moises RS. Long-term response to sulfonylurea in a patient with diabetes due to mutation in the KCNJ11 gene. Arq Bras Endocrinol Metabol 2010; 54: 682-684.

5. Iafusco D, Bizzarri C, Cadario F, et al. No beta cell desensitization after a median of 68 months on glibenclamide therapy in patients with KCNJ11-associated permanent neonatal diabetes. Diabetologia 2011; 54: 2736-2738.

6. Ješić MM, Ješić MD, Maglajlić S, Sajić S, Necić S. Successful sulfonylurea treatment of a neonate with neonatal diabetes mellitus due to a new KCNJ11 mutation. Diabetes Res Clin Pract 2011; 91: e1-e3.

7. Dahl A, Kumar A. Recent advances in neonatal diabetes. Diabetes Metab Syndr Obes 2020; 13: 355364.

8. Lemelman MB, Letourneau L, Greely SAW. Neonatal diabetes mellitus: an update on diagnosis and management. Clin Perinatol 2018; 45: 41-59.

9. De Franco E, Ellard S. Genome, exome, and targeted next-generation sequencing in neonatal diabetes. Pediatr Clin North Am 2015; 62: 1037-1053. 
10. Hattersley AT, Greeley SAW, Polak M, et al. ISPAD Clinical Practice Consensus Guidelines 2018: the diagnosis and management of monogenic diabetes in children and adolescents. Pediatr Diabetes 2018; 19(Suppl 27): 47-63.

11. Letourneau LR, Carmody D, Wroblewski K, et al. Diabetes presentation in infancy: high risk of diabetic ketoacidosis. Diabetes Care 2017; 40: e147-e148.

12. Zung A, Glaser B, Nimri R, Zadik Z. Glibenclamide treatment in permanent neonatal diabetes mellitus due to an activating mutation in Kir6.2. J Clin Endocrinol Metab 2004; 89: 5504-5507.

13. Pearson ER, Flechtner I, Njolstad PR, et al; Neonatal Diabetes International Collaborative Group. Switching from insulin to oral sulfonylureas in patients with diabetes due to Kir 6.2 mutations. N Engl J Med 2006; 355: 467-477.
14. Li X, Xu A, Sheng H, et al. Early transition from insulin to sulfonylureas in neonatal diabetes and follow-up: experience from China. Pediatric Diabetes 2018; 19: 251-258.

15. Bowman P, Sulen A, Barbetii F, et al; Neonatal Diabetes International Collaborative Group. Effectivness and safety of long-term treatment with sulfonylureas in patients with neonatal diabetes due to KCNJ11 mutations: an international cohort study. Lancet Diabetes Endocrinol 2018; 6: 637-646. 